\title{
Pengaruh Perceived Value, Perceived Quality dan Customer Satisfaction terhadap Customer Loyalty Warunk Upnormal di Jakarta
}

\author{
Koko Andianto dan Carunia Mulya Firdausy \\ Program Studi Manajemen Fakultas Ekonomi dan Bisnis \\ Universitas Tarumanagara \\ Email : kokodianto7@gmail.com
}

\begin{abstract}
Research is conducted to find out that there is a significant influence of the three variables, perceived value, perceived quality and customer satisfaction on Customer loyalty. This research was conducted based on the existence of a problem to consumer loyalty to a brand that is indicated due to perceived value, perceived quality and customer satisfaction. This research uses a descriptive research design through a quantitative approach with data collection using a survey method that produces 100 respondents through Google form. The sample in this study were consumers who had visited to make purchases and had visited at least two Warunk Upnormal outlets. The sample selection technique chosen in this study is the Convenience sampling technique. In this study, the findings show that the three independent variables studied were proven to have a significant influence on the dependent variable.
\end{abstract}

Keywords : Perceived value, quality, satisfaction and loyalty.

\begin{abstract}
Abstrak :Riset dilakukan guna mengetahui bahwa adanya pengaruh yang signifikan dari ketiga variabel, perceived value, perceived quality dan customer satisfaction terhadap Customer loyalty. Penelitian ini dilakukan berdasarkan adanya suatu masalah terhadap loyalitas konsumen atas sebuah merek yang terindikasi disebabkan oleh perceived value, perceived quality dan customer satisfaction. Penelitian ini menggunakan desain penelitian deskriptif melalui pendekatan kuantitatif dengan pengumpulan data menggunakan metode survei yang menghasilkan 100 responden melalui google form. Sampel pada penelitian ini adalah para konsumen yang pernah berkunjung untuk melakukan pembelian dan sudah pernah sedikitnya dua kali berkunjung ke gerai Warunk Upnormal. Teknik pemilihan sampel yang dipilih pada penelitian ini yaitu menggunakan teknik Convenience sampling. Dalam penelitian ini menghasilkan temuan bahwa ketiga variabel independen yang diteliti terbukti bahwa adnya pengaruh yang cukup signifikan terhadap variabel dependen.
\end{abstract}

Kata Kunci : Nilai yang dirasakan, kualitas yang dirasakan, kepuasan pelanggan dan loyalitas pelanggan.

\section{LATAR BELAKANG}

Perkembangan pada sektor food and beverages yang cukup pesat meningkat pada akhirakhir ini ditandai dengan menjamurnya bisnis restoran atau kafe di Indonesia khususnya Jakarta. Diketahui pula bahwa pertumbuhan setiap tahunnya dalam sektor ini terus meningkat dikarenakan segementasinya yang mudah dijangkau oleh pasar. Oleh karena itu penetrasi yang cepat pada sektor ini berdampak positif terhadap kontribusinya pada Indonesia. Banyaknya pemain baru pada sektor ini membuat beragamnya pilihan bagi konsumen, sehingga hal ini menyebabkan timbulnya pengaruh terhadap loyalitas pelanggan restoran atau kafe di Indonesia. 
Dibalik dari berbagai pilihan restoran atau kafe yang tersedia, namun terdapat pengaruh terhadap customer loyalty (loyalitas konsumen) dalam benak konsumen. Terdapat penurunan pada loyalitas konsumen dikarenakan beragamnya pilihan yang mungkin serupa antara jenis restoran satu dengan yang lainnya. Konsumen banyak beranggapan bahwa tidak ada inovasi yang besar dari restoran atau kafe pada saat ini.

Menurunnya perilaku loyalitas pada restoran terjadi dikarenakan konsumen menganggap bahwa tidak ada inovasi signifikan yang diberikan oleh restoran pada saat ini dan kadang kala nilai, kualitas bahkan tema yang diusung pun serupa. Pada dasarnya masyarakat Indonesia cukup sensitif terhadap harga yang mengakibatkan suatu produk dilihat dan dipertimbangkan cukup ketat yang mengakibatkan mudahnya para konsumen beralih kepada restoran lainnya. Semakin banyaknya pemain baru maka semakin turun pula tingkat loyalitas konsumen yang didapat dari suatu merek, hal alamiah ini terjadi karena konsumen akan beranggapan bahwa banyaknya pilihan maka mengapa harus loyal terhadap satu merek jika treatment yang diberikan serupa.

Menurut Oliver (1997) Customer loyalty merupakan komitmen yang dipegang teguh oleh pelanggan untuk membeli atau menggunakan produk maupun jasa tersebut kembali atau memastikan bahwa suatu produk atau layanan tersebut akan dipilih secara konsisten dimasa depan. Berdasarkan pernyataan diatas menggambarkan bahwa betapa pentingnya seorang pelanggan dimata penjual untuk keberlangsungan bisnisnya pada masa depan. Maka dari itu berdasarkan teori yang ada loyalitas terbentuk salah satunya dari kepuasan seorang konsumen, saat ini bisa dikatakan kurang bekerja pernyataan itu. Konsumen menginginkan hal dan konsep yang unik yang memberikan nilai yang berbeda dari kompetitor lainnya.

Oleh karena itu, novelty yang terdapat pada penelitian ini adalah bahwa loyalitas konsumen tidak hanya berpusat pada kepuasan maupun harga dari suatu produk, melainkan nilai yang didapat serta kualitas yang menjadi bahan pertimbangan konsumen untuk menempatkan suatu merek dalam benak hatinya seringkali para pelaku usaha lebih condong untuk menekankan harga agar terlihat murah dengan cara menurunkan kualitas dari produknya. Hal seperti inilah yang membuat pelanggan biasanya kecewa dan kapok tidak ingin mengkonsumsi lagi suatu produk tersebut. Oleh karena itu, penelitian ini ingin menunjukkan bahwa nilai yang terkandung dalam produk, maupun kualitas yang tinggi atas suatu produk tersebut lebih penting daripada hal hal tersebut diatas.

\section{KAJIAN TEORI}

Menurut Nilson (1992) Perceived value merupakan persepsi konsumen yang mengenai pemahaman dari manfaat suatu produk. Ini juga melibatkan tentang bagaimana pelanggan menilai bahwa produk tersebut sesuai dengan apa yang mereka harapkan, Goyhenetche (1999). Untuk meningkatkan nilai yang dirasakan pelanggan dari suatu produk maupun layanan sebaiknya perusahaan menambahkan manfaat dari produk atau layanan tersebut dan mengurangi biaya agar bisa menekan harga beli oleh pelanggan atas suatu produk maupun layanan, Lovelock dan Wirtz (2007). Cronin et al, (2000) menyatakan bahwa perceived value yang dirasakan oleh konsumen atau suatu produk memiliki efek langsung kepada suatu perilaku yang biasa disebut konsep loyalitas. Tingginya nilai yang didapatkan konsumen akan mengarah pada retensi yang tinggi oleh pelanggan Naumann, (1995). Hasil yang diperoleh dari perceived value dapat dinyatakan secara empiris yaitu customer satisfaction dan customer loyalty menurut (Brodie et al, 2009, Gallarza dan Gil, 2006, Hutchinson et al, 2009).

Snoj (2004) mengatakan bahwa perceived quality dapat didefinisikan sebagai hasil penilaian dari seorang konsumen atau pelanggan mengenai produk atau jasa tersebut dengan mempertimbangkan superiority maupun keunggulan. Perceived quality adalah variabel mengenai penilaian sebuah produk secara keseluruhan yang bersifat subjektif atas 
keunggulan dari produk tersebut, (Zeithaml dalam Yoo, Donthu, Lee, 2000). Sejalan dengan itu Kotler (2009: 143) menyatakan "The overall characteristics and nature of a product or service are questioned in its ability to meet the agreed or implied needs". Menurut penelitian yang dilakukan oleh Lee (1998), studi dilakukan untuk mengetahui sebuah kualitas akan mempengaruhi kepuasan dan loyalitas pelanggan yang mana mengejutkan bahwa sebuah kualitas layanan atau produk yang didapatkan konsumen dapat memengaruhi secara langsung kepada perilaku pembelian ulang para pelanggan. Pembelian ulang merupakan salah satu karakteristik tanda bahwa seorang pelanggan sudah menaruh produk tersebut dibenak hatinya, yang dikutip dari Griffin (2005: 65).

Menurut Oliver (1980) Customer satisfaction merupakan bentuk dari sikap yang dihasilkan atas perbandingan dari ekspektasi kinerja dengan apa yang konsumen dapat dari layanan yang diberikan. Kepuasan yang dialami oleh konsumen didapatkan dari hasil mengevaluasi produk maupun layanan yang mereka dapatkan atau mereka konsumsi. Menurut Kotler (2005) definisi dari Customer satisfaction merupakan dimana seseorang membandingkan hasil dari apa yang dirasakan oleh suatu produk atau layanan dengan harapan seseorang tersebut terhadap produk. Menurut Heskett et al, (1997) menyatakan bahwa customer satisfaction merupakan premis penting untuk mencapai customer loyalty serta sebagai pendorong untuk meningkatkan sektor finansial. Sudah sekian lama telah terbukti bahwa meningkatnya customer satisfaction dapat memastikan loyalnya konsumen terhadap produk yang memastikan keunggulan kompetitif serta kesuksesan jangka panjang Ali et al, (2016). Berdasarkan bahasan diatas memang kepuasan adalah pemicu seorang konsumen untuk melakukan pembelian ulang, yang nantinya jika kepuasan itu terus menerus dirasakan oleh konsumen akan timbul rasa loyal terhadap produk tersebut.

Menurut Oliver (1997) Customer loyalty merupakan komitmen yang dipegang teguh oleh pelanggan untuk membeli atau menggunakan produk maupun jasa tersebut kembali atau memastikan bahwa suatu produk atau layanan tersebut akan dipilih secara konsisten dimasa depan. Definisi tersebut memfokuskan kepada perilaku maupun sikap kesetiaan pelanggan. Pelanggan bisa saja loyal terhadap suatu produk atau layanan dikarenakan terbatasnya pilihan maupun ketersediaan produk atau layanan yang sedikit Bloemer and Kasper, (1995). Konsumen akan membentuk kepercayaan mereka terhadap suatu produk maupun layanan melalui pengalaman yang mereka rasakan.

Berdasarkan uraian di atas dibuatlah kerangka konseptual seperti gambar 1 .

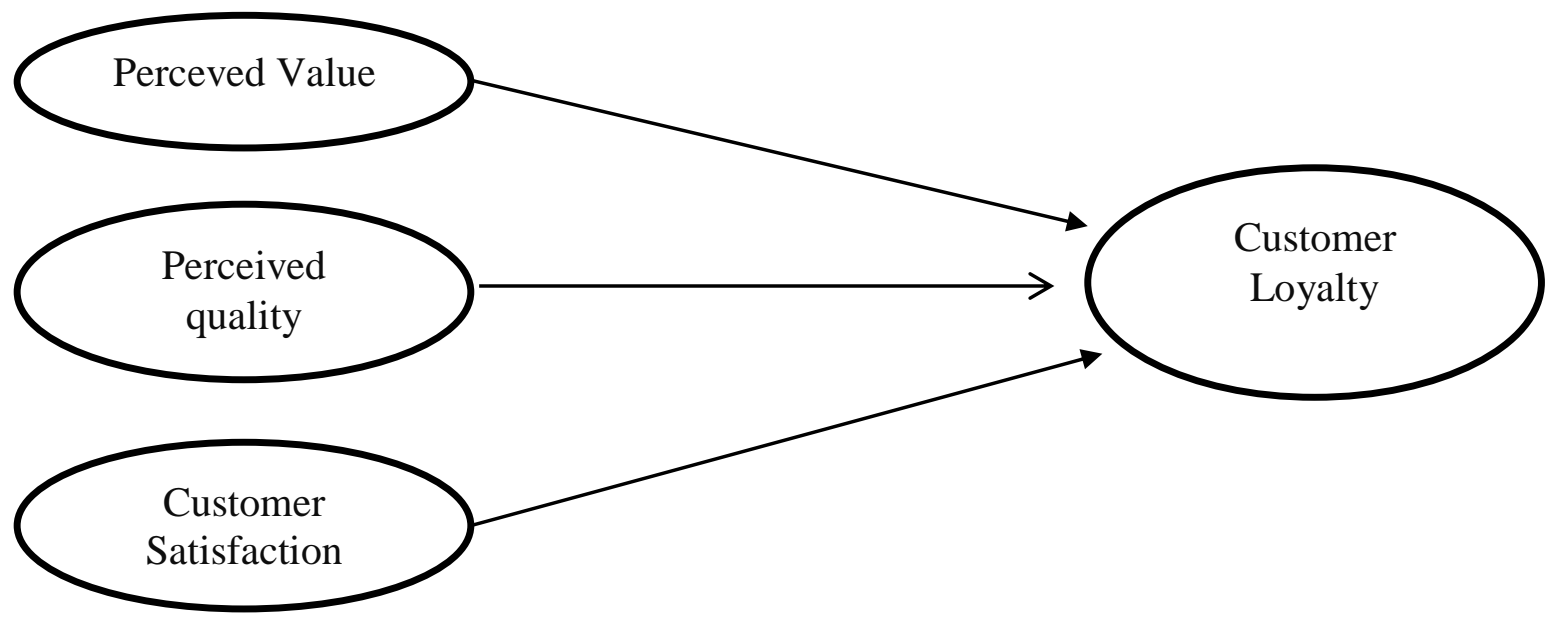

Gambar 1. Kerangka Pemikiran 


\section{Hipotesis}

Hipotesis adalah suatu dugaan sementara mengenai perilaku, peristiwa atau keadaan tertentu yang sudah terjadi (Kuncoro, 2013:78). Maka dari itu melalui penguraian diatas, hipotesis alternatif adalah sebagai berikut :

H1: Terdapat pengaruh yang positif dari Perceived value terhadap Customer loyalty di gerai Warunk Upnormal

H2: Terdapat pengaruh yang positif dari Perceived quality terhadap Customer loyalty di gerai Warunk Upnormal

H3: Terdapat pengaruh yang positif dari Customer satisfaction terhadap Customer loyalty di gerai Warunk Upnormal

Mengenai penelitian yang relevan, penulis menggunakan salah satu penelitian yang sudah dilakukan oleh Krishna Moorthy, Loh Chun T'ing, Seow AiNa, Chew Tze Ching, Lee Yuin Loong, Lim Sze Xian dan Teoh Wei Ling (2017) untuk dijadikan acuan. Tetapi penulis menggunakan model yang berbeda guna mengisi kekosongan literatur serupa. Maka dari itu adanya penelitian ini mempunyai novelty yang nantinya diharapkan dapat berguna oleh pembaca. Hasilnya tidak jauh beda yang mana dari ketiga variabel independen penelitian ini berpengaruh positif terhadap variabel dependen.

\section{METODOLOGI}

Penelitian ini adalah penelitian berjenis kuantitatif dengan metode penelitian deskriptif. Populasi dalam penelitian ini adalah seluruh pelanggan Warunk Upnormal di Jakarta. Metode pengambilan sampel dalam penelitian ini adalah metode non-probability sampling yang artinya tidak semua orang memiliki kesempatan yang sama untuk terpilih sebagai sampel.

Sementara untuk teknik pemilihan sampling dalam penelitian ini adalah convenience sampling. Sampel dalam penelitian ini sebesar 100 sampel. Berdasarkan data yang telah dikumpulkan, diketahui bahwa karakteristik responden dalam penelitian ini berdasarkan jenis kelamin, dari total responden yang berjumlah 100 orang, sebesar (48\%) adalah berjenis kelamin pria dan $(52 \%)$ berjenis kelamin perempuan. Untuk karakteristik responden berdasarkan usia <17 tahun sebesar (5\%), 17-20 tahun sebesar (25\%), 21-25 tahun sebesar (72\%) dan 25-30 tahun (3\%). Untuk karakteristik responden berdasarkan pekerjaan pelajar/mahasiswa (85\%), pegawai negri (1\%), dan lainnya (14\%).

Pengukuran objek penelitian diukur menggunakan skala Likert empat poin dengan 1 menunjukan "sangat tidak setuju" dan 4 menunjukan "sangat setuju". Data dapat dikatakan valid jika nilai convergent validity adalah nilai loading factor (LF) pada variabel laten dengan indikator - indikatornya. Nilai loading factor yang diharapkan atau dikatakan > 0,7. Discriminant validity adalah nilai cross loading factor yang digunakan untuk mengetahui apakah konstruk memiliki diskriminan yang memadai dengan cara membandingkan nilai loading pada konstruk yang dituju harus lebih besar dibandingkan dengan nilai loading dengan konstruk lain. Discriminant validity dapat dianggap tercapai apabila nilai AVE lebih besar daripada nilai korelasi diantara variabel laten, yaitu 0,50. Tiap pernyataan dapat dikatakan reliable jika nilai Cronbach's alpha lebih besar atau sama dengan 0,60 dan tiap pernyataan yang memiliki nilai Composite Reliability lebih besar atau sama dengan 0,70, 
Koko Dan Carunia : Pengaruh Perceived Value, Perceived Quality...

maka pernyataan yang mengukur variabel tersebut dapat diterima.

Tabel 1. Variabel data pengukuran

\begin{tabular}{|c|c|c|}
\hline Variabel & $\begin{array}{c}\text { Jumlah } \\
\text { Item }\end{array}$ & Sumber \\
\hline Perceived Value & 3 & Yang et al. (2015) \\
\hline Perceived Quality & 4 & Grewal et al, (1998). \\
\hline Customer Satisfaction & 3 & Croninetal (2000) \\
\hline Customer Loyalty & 5 & Kuo-Chien Chang (2010) \\
\hline
\end{tabular}

\section{HASIL UJI STATISTIK}

Pada penelitian ini, pengujian data dilakukan dengan menggunakan uji Bootstrapping untuk menguji kedua hipotesis. Adapun pengujian tersebut dilakukan untuk mendapatkan bukti adanya pengaruh positif atau tidak berpengaruh postif perceived value, perceived quality dan customer satisfaction terhadap customer loyalty Warunk Upnormal di Jakarta. Hasil analisis data secara singkat tertera pada Tabel 2. berikut ini:

Tabel 2. Hasil Pengujian Hipotesis

\begin{tabular}{|l|l|l|}
\hline Hipotesis & $\begin{array}{l}\text { Hasil } \beta, \text { p-value dan T- } \\
\text { statistic }\end{array}$ & Keterangan \\
\hline $\begin{array}{l}\mathrm{H}_{1}: \text { Terdapat pengaruh yang } \\
\text { positif dari Perceived value } \\
\text { terhadap Customer loyalty }\end{array}$ & $\begin{array}{l}\beta=0,287 \\
\mathrm{p} \text {-value }=0,002 \\
\mathrm{~T} \text {-statistic }=2,967\end{array}$ & Hipotesis didukung \\
\hline $\begin{array}{l}\mathrm{H}_{2}: \text { Terdapat pengaruh yang } \\
\text { positif dari Perceived quality } \\
\text { terhadap Customer loyalty }\end{array}$ & $\begin{array}{l}\beta=0,337 \\
\mathrm{p} \text {-value }=0,005\end{array}$ & T-statistic =2,627 \\
\hline $\begin{array}{l}\mathrm{H}_{3}: \text { Terdapat pengaruh yang } \\
\text { positif dari Customer } \\
\text { satisfaction p-value }=0,003 \\
\text { Customer loyalty terhadap }\end{array}$ & $\begin{array}{l}\text { T-statistic }=2,777 \\
\text { Tumbis didukung }\end{array}$ & Hipotesis didukung \\
\hline
\end{tabular}

Sumber: SmartPLS 3 for Windows

\section{Diskusi}

Dapat dilihat pada tabel 2, hasil pengujian hipotesis Perceived value terhadap Customer loyalty di Jakarta memiliki nilai koefisien beta yaitu sebesar 0,287, nilai T-statistic yaitu sebesar 2,967 dan P-values sebesar 0,002 yang berarti H1 tidak ditolak dan dapat diartikan bahwa variabel perceived value memiliki pengaruh positif terhadap customer loyalty Warunk Upnormal di Jakarta. Dalam hal ini perceived value terbukti dapat mempengaruhi loyalitas konsumen di Warunk Upnormal karena sejatinya sebuah produk yang terdapat nilai yang diharapkan oleh konsumen yang mengkonsumsinya dapat memberikan efek positif terhadap persepsi yang dibentuk konsumen. Nilai inilah yang dapat memberikan kepuasan pada konsumen lalu menimbulkan rasa kesetiaan terhadap merek tersebut. Hal yang menjadi ujian untuk pelaku usaha adalah mempertahankan bahkan harus meningkatkan juga nilai yang terdapat di produk tersebut, karena kecenderungan untuk beralih ke merek lain cukup tinggi jika terdapat penurunan dari nilai-nilai yang biasanya terdapat pada produk.

Dapat dilihat pada tabel 2, hasil pengujian hipotesis perceived quality terhadap customer loyalty di Jakarta memiliki nilai koefisien beta yaitu sebesar 0,337, nilai T-statistic yaitu sebesar 2,627 dan P-values sebesar 0,005 yang berarti $\mathrm{H} 2$ tidak ditolak dan dapat diartikan bahwa perceived quality berperan andil untuk menimbulkan konsumen untuk loyal 
terhadap suatu merek. Kualitas adalah salah satu kunci utama bagi keberhasilan suatu usaha mempertahankan konsumennya. Kualitas merupakan salah satu pengukuran terpenting untuk mempertimbangkan apakah suatu merek dapat menjadi pilihan yang tepat bagi seorang konsumen. Pada dasarnya kualitas yang tinggi pun dapat menjadi pisau bermata dua bagi suatu usaha, dikarenakan standarisasi yang tinggi tetapi tidak di ikuti maintenance yang sustainable dapat menimbulkan kekecewaan bagi konsumen. Maka dari itu kualitas harus konsisten dipertahankan dengan standarisasi yang ditetapkan sebagai upaya mempertahankan loyalitas dari konsumen.

Dapat dilihat pada tabel 2, hasil pengujian variabel customer satisfaction terhadap customer loyalty di Jakarta memiliki nilai koefisien beta yaitu sebesar 0,288, nilai T-statistic yaitu sebesar 2,777 dan P-values sebesar 0,003 yang berarti $\mathrm{H} 3$ tidak ditolak dan dapat diartikan bahwa variabel customer satisfaction memiliki pengaruh positif terhadap customer loyalty. Kepuasan konsumen adalah bentuk dari gambaran seorang konsumen dapat menaruh kesetiaannya terhadap suatu merek. Alamiahnya memang seorang konsumen loyal terhadap suatu merek disebabkan adanya kepuasan yang ia dapat dari suatu produk. Oleh karena itu kepuasan menjadi tujuan utama pelaku bisnis untuk memberikan yang terbaik untuk produknya agar melekat didalam benak hati para konsumennya. Dapat dikatakan kepuasan konsumen adalah nilai mutlak bagi suatu produk dan harus dipertahankan guna menjaga perilaku loyal pelanggannya.

\section{KESIMPULAN}

Telah diketahui bahwa penelitian ini menunjukan adanya pengaruh antara perceived value, perceived quality dan customer satisfaction terhadap customer loyalty digerai Warunk Upnormal. Hasil penelitian ini dapat digunakan oleh pelaku usaha khususnya Warunk Upnormal atau umumnya masyarakat luas yang ingin memulai ataupun sudah mempunyai bisnis. Penelitian ini berguna sebagai sarana untuk mempertahankan dan meningkatkan nilai maupun kualitas yang telah diberikan sekian tahun belakangan ini oleh Warunk Upnormal sehingga perilaku loyal dari konsumen terus menigkat setiap saatnya.

Selain itu, melalui frekuensi jawaban yang diberikan oleh responden untuk variabel Perceived quality pada pernyataan "Menurut saya produk makanan/minuman yang saya beli dan konsumsi dari kafe Warunk Upnormal merupakan produk yang baik dan layak" sebanyak 59\% responden menjawab setuju dan 40\% responden menjawab sangat setuju, hal tersebut menunjukan bahwa persepsi yang diberikan oleh konsumen terhadap kualitas produk ialah positif yang dimana menunjukan bahwa kesempatan untuk mendapatkan kesetiaan atau loyalitas dari konsumen terbuka lebar. Hasil penelitian ini dapat menambah referensi untuk penelitian mengenai perceived value, perceived quality, customer satisfaction dan customer loyalty pada objek maupun subjek yang lain.

\section{SARAN}

Berdasarkan penelitian yang telah dilakukan, ada beberapa saran yang dapat dipertimbangkan untuk penelitian selanjutnya agar menghasilkan informasi yang lebih baik dan sempurna, yaitu :

a. Penelitian selanjutnya diharapkan menyertakan variabel lain yang mungkin berpengaruh terhadap variabel dependen, dikarenakan masih ada $35 \%$ variabelvariabel lain diluar dari variabel yang terdapat dipenelitian ini yang dapat menjelaskan lebih terperinci. 
b. Penelitian yang selanjutnya diharapkan dapat melakukan penelitian dengan model yang lebih bervariasi atau mengembangkan dari model-model penelitian yang sudah ada. Sehingga dapat menghasilkan sebuah penelitian yang memberikan gambaran yang cukup jelas dan baik dari sebelumnya.

c. Indikator yang harus diperhatikan adalah indikator x2.4 dan x3.2 yang mana mempunyai nilai cross loading lebih kecil daripada nilai indikator lainnya. Hal ini diharapkan dapat diteliti oleh penelitian berikutnya guna mendapatkan sebuah temuan mengapa indikator tersebut mendapatkan nilai cross loading yang kecil yang menggambarkan adanya masalah pada faktor tersebut.

\section{DAFTAR PUSTAKA}

Oliver, Riscrd L, (1997), Satisfaction A Behavioral Perspective On The Consumer. McGraw-Hill Education, Singapore.

Bloemer dan J. Kasper. (1995). The complex relationship between consumer satisfaction and brand loyalty. Journal of Economic Psychology, 16(2):19-24

Kotler, Philip dan Keller. (2009). Manajemen Pemasaran. Jilid 1. Jakarta: Erlangga

Griffin, Jill, (2005). Customer Loyalty: Menumbuhkan dan Mempertahankan Kesetiaan Pelanggan, Erlangga, Jakarta.

H Ana ,M. Castillo, C. \& Juan Antonio, J. (2017). Quality, Satisfaction and Loyalty Indices. Journal of Place Management and Development, 11(4), 428-446.

Krishna, M, Chun. T, Seow. A, Chew T, C. Lee Y, L. Lim, X. and Teoh W. (2017). Corporate Image no longer leads to customer satisfaction and loyalty: a Malaysian perspective. International Journal of Law and Managemet, 60(4), 934-952.

Jackie L, Tam. (2010). The moderating role of perceived risk in loyalty intentions: an investigation in a service context. Marketing Intelligence \& Planning, 30(1), 33-52

Vanessa Quintal and Ian Phau. (2012). Brand leaders and me-too alternatives: how do consumers choose?. Marketing Intelligence \& Planning, 31(4), 367-387.

Lien-Ti B, Yu-Ching Chiao. (2006). The determinants of customer loyalty: an analysis of intangibile factors in three service industries. IJCM, 16(3\&4), 162-176.

Kotler, Philip \& Kevin Lane Keller. (2012). Manajemen Pemasaran. Jilid 2, Edisi 13. Terjemahan Bob Sabran. Jakarta: Penerbit Erlangga.

Prasanta Kr, C and V. J. Sivakumar. (2017). Understanding psychological contract violation and its consequences on mobile shopping applications use in a developing country context. Journal of Indian Business Research, 10(2), 208-231.

Jin-Wook Han. (2009). The mediating effect of perceived quality between extrinsic cues and perceived value in ski products. International Journal of Sports Marketing \& Sponsorship. $18-32$.

Barbara $\mathrm{C}$ ater and Tomaz ${ }^{\sim} \mathrm{C}$ vater. (2008). Relationship-value-based antecedents of customer satisfaction and loyalty in manufacturing. Journal of Business \& Industrial Marketing. 24(8), 585-597.

Osman Gök. Pervin, E. Gülmüs, B. (2018). The effect of user manual quality on customer satisfaction: the mediating effect of perceived product quality. Journal of Product \& Brand Management, 28(4), 475-488. 